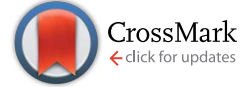

Cite this: RSC Adv., 2017, 7, 15931

Received 19th February 2017

Accepted 6th March 2017

DOI: $10.1039 / c 7 r a 02070 h$

rsc.li/rsc-advances

\section{Differential effects of in vitro cultures of Linum usitatissimum L. (Flax) on biosynthesis, stability, antibacterial and antileishmanial activities of zinc oxide nanoparticles: a mechanistic approach}

\begin{abstract}
Bilal Haider Abbasi, ${ }^{* a}$ Sumaira Anjum ${ }^{a}$ and Christophe Hano ${ }^{b}$
The use of plants and plant-derived materials for biosynthesis of zinc oxide nanoparticles (ZnO NPs) is developing into a lucrative field of green nanotechnology and gaining more importance owing to its simplicity, rapidity, and eco-friendliness. In present study, a novel and efficient green approach has been developed for biosynthesis of ZnO NPs by exploiting the in vitro platform of plants. Two different in vitro cultures extracts i.e.; callus extract (CE) and adventitious root extract (RE) of Flax were used as a source of reducing and stabilizing agents. Phytochemical analysis revealed that the RE was rich in phytochemical reducing agents as compared to CE. UV-visible spectroscopy showed that the bioreduction of RE-mediated ZnO NPs completed in shorter time than CE-mediated ZnO NPs. Scanning electron microscopy showed that CE-mediated ZnO NPs were spherical with weak agglomeration but the RE-mediated ZnO NPs were hexagonal in shape with uniform distribution of particles. X-ray diffraction analysis showed that the both type of ZnO NPs exhibited the same crystalline nature (wurtzite hexagonal) but vary in their sizes. RE-mediated ZnO NPs were smaller in size $(34.97 \mathrm{~nm})$ than CEmediated ZnO NPs $(61.44 \mathrm{~nm})$. Fourier-transform infrared spectroscopy revealed that the polyphenols (lignans), carboxylic acids and aromatic compounds were mainly involved in reduction and capping of both type of ZnO NPs. Moreover, the RE-mediated ZnO NPs showed more potent antibacterial and antileishmanial activity against multidrug resistant bacterial strains and parasite of Leishmania major than CE-mediated ZnO NPs. The present work highlighted the potent role of in vitro cultures of Flax in enhanced biosynthesis, antibacterial and antileishmanial activities of ZnO NPs.
\end{abstract}

\section{Introduction}

Nanotechnology is an emerging area of modern research, which revolutionizes all the fields of science by synthesizing new materials at the nanoscale level. These nanoscale materials are called a "wonder of modern medicine".,2 Among different nano-materials, the synthesis of metal oxide nanoparticles is one of the most dynamic areas of research in the field of modern material sciences. Due to the unique physico-chemical properties of nanoparticles, their applications are growing rapidly in various fields such as electronics, catalysis, optics, drug delivery, tissue engineering, gene delivery, environmental, food industry, space industry, and antimicrobial. ${ }^{3-6}$

Due to the outbreak of infectious diseases and the development of antibiotic-resistant strains, scientists are searching for new antimicrobial agents. Among different infectious diseases,

${ }^{a}$ Department of Biotechnology, Quaid-i-Azam University, Islamabad-45320, Pakistan. E-mail: bhabbasi@qau.edu.pk; Fax: +92-51-90644121; Tel: +92-51-90644121

${ }^{b}$ Laboratoire de Biologie des Ligneux et des Grandes Cultures (LBLGC), Université d'Orléans, UPRES EA 1207, Chartres, France
Leishmaniasis is a serious public health problem and is currently endemic in 98 countries all over the world. ${ }^{7}$ Currently, the drugs used in the treatment of Leishmaniasis have several disadvantages such as expensiveness, drug-resistant and toxicity to human cells. ${ }^{8,9}$ To overcome these issues, there is an urgent need to search for new antileishmanial agents that can effectively kill the parasites causing Leishmaniasis. In the present scenario, zinc oxide nanoparticles (ZnO NPs) have emerged up as novel antimicrobial and antileishmanial agents owing to their high surface area to volume ratio, enhanced optical properties and ability to generate reactive oxygen species (ROS) inside the microbial cells. ${ }^{\mathbf{1 0 , 1 1}} \mathrm{ZnO}$ NPs have also found marvelous application in biosensors, solar cells, semiconductors, agriculture, cosmetics, drug delivery, diagnostics and bio-imaging probes. ${ }^{\mathbf{1 2 - 1 4}}$ In spite of these merits, ZnO NPs are also bio-safe and biocompatible with unique structural, electrical and thermal properties, which could be varied with respect to particle size, shape, morphology, and orientation. ${ }^{\mathbf{1 5 , 1 6}}$

For synthesis of ZnO NPs, numerous physical and chemical approaches have been reported previously. ${ }^{17-19}$ Most of these approaches are environmentally un-friendly, generate 
hazardous wastes and require high vacuum, expensive chemicals, sophisticated equipment, high energy source, and laborious experimental conditions. ${ }^{19}$ To mitigate the above stated problems, there is an urgent need of a new simple and ecofriendly green synthesis process. Among different green synthesis approaches, the use of plant extracts is one of the most implemented method of green, eco-friendly fabrication of nanoparticles and also has a distinctive advantage that the plants are extensively distributed, easily accessible and less biohazardous. ${ }^{2,16}$ Moreover, the nanoparticles produced by plants are more stable and more varied in shape and size in comparison with those produced by other organisms. ${ }^{16,20}$ Plant extracts are natural reservoirs of several phytochemicals which help in the bioreduction and capping of the synthesized nanoparticles. ${ }^{21,22}$ Nature of plant extracts affect the morphology and physico-chemical properties of the synthesized nanoparticles, because they differ in their bioreduction capacity owning to their different levels of phytochemicals. ${ }^{20,23}$

Linum usitatissimum L. (Flax), is one of the oldest and highly cultivated oilseed crop in Europe and is regarded as a functional food due to presence of high quality omega-3 fatty acids ( $\alpha$ linolenic acid), proteins, lignin, phenolic acids, and dietary fibers, etc. $^{\mathbf{2 4 , 2 5}}$ Flax seeds are used in various medicine due to the presence of biologically active components (lignans), which exhibit both phytoestrogenic and antioxidant properties. ${ }^{26}$ Secoisolariciresinol diglucoside (SDG), matairesinol (MAT), secoisolariciresinol (SECO) and lariciresinol diglucoside (LDG) are the main lignans present in this plant species. These lignans help in the prevention and treatment of various types of cancers especially the breast, prostate and colon cancers. ${ }^{27,28}$ Besides lignans, Flax is also a good source of neolignans (dehydrodiconiferyl alcohol glucoside, DCG; and guaiacylglycerol- $\beta$ coniferyl alcohol ether glucoside, GGCG), which are used as principal agents in antifungal and antiinflammatory medicines. ${ }^{29}$ Flax is a rich source of lignans and neolignans which can act as reducing agents as well capping agents in synthesis of ZnO NPs. Previously, the use of extracts of various wild grown plants such as Calotropis procera, Ocimum basilicum L., Parthenium hysterophorus L., Citrus aurantifolia, Plectranthus amboinicus and Trifolium pratense have been reported for the green synthesis of $\mathrm{ZnO} \mathrm{NPs}^{30-35}$ But, unfortunately no report is available on the role of in vitro-derived cultures of plants in synthesis of ZnO NPs.

Plant in vitro cultures can offer an alternative platform for enhanced production of biochemical reducing agents, which are either difficult to extract from field grown plants or their production is limited by various environmental factors. ${ }^{36,37}$ Manipulation of in vitro cultures of plants in green synthesis of nanoparticles can speed up the reduction process of metallic ions by improving the phytochemical reducing potential of extracts. $^{38}$ Both differentiated (adventitious root and cell suspension) and non-differentiated (callus) in vitro cultures can be used as a source of reducing and capping agents for synthesis of nanoparticles. These in vitro cultures vary in their bioreduction potential owing to their different levels of biochemical reducing agents. Among different in vitro cultures, adventitious root culture can serve as a promising source for stable and enhanced production of biochemical reducing agents. $^{39}$ Moreover, adventitious root cultures are easy to maintain and have high proliferation rates than other cultures. ${ }^{40}$ In present study, we reported a novel, safe and rapid method for the biosynthesis of ZnO NPs. The main objective of this study was to explore the potential role of in vitro cultures of Flax in synthesis, antibacterial and antileishmanial properties of ZnO NPs. For this purpose, two different types of in vitro culture have been used for synthesis of ZnO NPs i.e.; callus extract (CE) and adventitious root extract (RE). Biosynthesized ZnO NPs were further characterized by different techniques and were evaluated for their potential antibacterial and antileishmanial effects. Furthermore, we have also demonstrated a captivating approach to vibrantly understand the mechanisms involved in the synthesis and antimicrobial activity of ZnO NPs. To the best of our knowledge, this is the first study that utilizes the in vitro-derived cultures of Flax for the biosynthesis of $\mathrm{ZnO}$ NPs.

\section{Materials and methods}

\subsection{Plant material and establishment of callus culture}

Flax seeds (brown variety) were collected from natural habitat of District Swat, Pakistan. Seeds were surface sterilized and inoculated on Murashige and Skoog basal medium (MS0) ${ }^{\mathbf{4 1}}$ according to the method of Anjum and Abbasi. ${ }^{42}$ For establishment of callus culture, root ( $\sim 1$ to $2 \mathrm{~cm}$ ) explants were collected from 30 days old in vitro plantlets of Flax and cultured on MS media containing sucrose $\left(30 \mathrm{~g} \mathrm{l}^{-1}\right)$, agar $\left(8 \mathrm{~g} \mathrm{l}^{-1}\right)$ and various concentration $\left(0.5-3.0 \mathrm{mg} \mathrm{l}^{-1}\right)$ of $\alpha$-naphthalene acetic acid (NAA), indole butyric acid (IBA), indole acetic acid (IAA), and 2,4-dichlorophenoxyacetic acid (2,4-D). MS medium without any plant growth regulators (PGRs) was used as control. The $\mathrm{pH}$ of all media was adjusted to $5.6 \pm 0.2$ prior to autoclaving $\left(121{ }^{\circ} \mathrm{C}\right.$ for $\left.20 \mathrm{~min}\right)$. These cultures were maintained at $25 \pm 2{ }^{\circ} \mathrm{C}$ for $16 / 8 \mathrm{~h}$ (light/dark) photoperiod in growth chamber. For each concentration of PGRs used, experiment was performed in triplicate culture flasks and whole of the experiment was repeated twice. Calli were harvested from the culture media after 4 weeks of culture and investigated for their biomass accumulation and photochemical analysis. Data regarding these parameters of calli (data not shown) revealed that, the callus obtained in response to $1.0 \mathrm{mg} \mathrm{l}^{-1}$ NAA treatment showed highest accumulation of biomass and phytochemicals. On the basis of these parameters, callus induced in response to $1.0 \mathrm{mg}$ $\mathrm{I}^{-1}$ NAA was selected for biosynthesis of ZnO NPs.

\subsection{Establishment of adventitious root culture}

For establishment of adventitious root culture, $\operatorname{root}(\sim 2$ to $3 \mathrm{~cm})$ explants were transferred into MS liquid media containing $30 \mathrm{~g}$ $\mathrm{l}^{-1}$ of sucrose and various concentrations $\left(0.5-3.0 \mathrm{mg} \mathrm{l}^{-1}\right)$ of IAA, IBA, and NAA. These cultures were maintained in flasks $(100 \mathrm{ml})$ with $40 \mathrm{ml}$ of culture medium on a rotary shaker at $100 \mathrm{rpm}$, at $25 \pm 2{ }^{\circ} \mathrm{C}$ in darkness. MS0 without any PGRs was used as a control. For each concentration of PGRs used, experiment was performed in triplicate culture flasks and whole 
of the experiment was repeated twice. Adventitious roots formed in response to different concentrations of PGRs, were harvested from the liquid culture media after 6 weeks of culture and investigated for their biomass accumulation and photochemical analysis. Data regarding these parameters of adventitious roots (data not shown) revealed that, the roots obtained in response to $0.5 \mathrm{mg} \mathrm{l}^{-1}$ NAA treatment showed highest accumulation of biomass and phytochemicals. On the basis of these parameters, roots formed in response to $0.5 \mathrm{mg} \mathrm{l}^{-1}$ NAA were selected for biosynthesis of ZnO NPs.

\subsection{Extracts preparation}

For callus extract (CE) and root extract (RE) preparation, $10 \mathrm{~g}$ of freshly harvested callus and roots were separately mixed with $100 \mathrm{ml}$ of distilled water and boiled for $10 \mathrm{~min}$ in a $500 \mathrm{ml}$ flask. This process was repeated thrice with an interval of $30 \mathrm{~min}$ and resulted mixtures were placed in an incubator for $24 \mathrm{~h}$ at $40^{\circ} \mathrm{C}$. After that, these mixtures were allowed to cool down at room temperature and filtered twice through a filter paper. The volume of the filtrates were adjusted to $100 \mathrm{ml}$ with distilled water (Fig. 1) and stored at $4{ }^{\circ} \mathrm{C}$ for further use.

\subsection{Phytochemical analysis}

Total phenolic content (TPC) TPC was determined by using Folin-Ciocalteu (FC) reagent according to the method reported by Velioglu et al. ${ }^{43}$ Briefly, $20 \mu \mathrm{l}$ of the extracted sample (callus and root) was mixed with $90 \mu \mathrm{l}$ of the FC reagent $(10 \times$ diluted with distilled water) and incubated for $5 \mathrm{~min}$ at room temperature $\left(25 \pm 2{ }^{\circ} \mathrm{C}\right)$. After incubation, $90 \mu \mathrm{l}$ of sodium carbonate $(6 \%, \mathrm{w} / \mathrm{v})$ was added to above mixture and absorbance was measured at $725 \mathrm{~nm}$ by using UV-Visible spectrophotometer (Shimadzu-1650; Japan). Gallic acid $\left(0-50 \mu \mathrm{g} \mathrm{ml}{ }^{-1}\right)$ was used as standard for plotting calibration curve $\left(R^{2}=0.967\right)$ and the TPC was expressed as gallic acid equivalents (GAE) per $\mathrm{g}$ of DW.

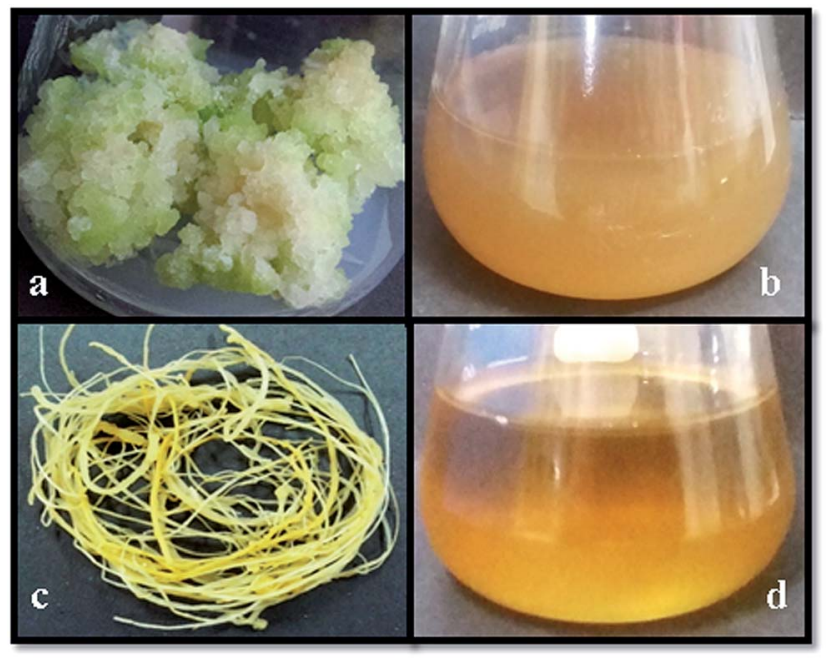

Fig. 1 In vitro-derived cultures and extracts of Flax. (a) Callus induced from root explant in response to $1.0 \mathrm{mg} \mathrm{l}^{-1} \mathrm{NAA}(\mathrm{b})$ aqueous callus extract (CE) (c) adventitious roots induced from root explant in liquid media in response to $0.5 \mathrm{mg} \mathrm{l}^{-1} \mathrm{NAA}(\mathrm{d})$ aqueous root extract (RE).
Total flavonoid content (TFC) was determined by using aluminum chloride $\left(\mathrm{AlCl}_{3}\right)$ colorimetric method reported by Cheng et al. ${ }^{44}$ Briefly, $20 \mu \mathrm{l}$ of the extracted sample (callus and root) was mixed with $10 \mu \mathrm{l}$ of potassium acetate $(1 \mathrm{M})$ and $10 \mu \mathrm{l}$ of $\mathrm{AlCl}_{3}(10 \%, \mathrm{w} / \mathrm{v})$. This mixture was incubated for $30 \mathrm{~min}$ at room temperature $\left(25 \pm 2{ }^{\circ} \mathrm{C}\right)$ after addition of $160 \mu \mathrm{l}$ of distilled water. Absorbance of the reaction mixture was measured at $415 \mathrm{~nm}$ by using UV-Visible spectrophotometer (Shimadzu1650 ; Japan). Quercetin $\left(0-50 \mu \mathrm{g} \mathrm{m} l^{-1}\right)$ was used as standard for plotting calibration curve $\left(R^{2}=0.988\right)$ and the TFC was expressed as quercetin equivalents $(\mathrm{QE})$ per $\mathrm{g}$ of $\mathrm{DW}$.

Lignans (SDG and LDG) and neolignans (DCG and GGCG) extraction procedure was based on the method derived from Corbin et al. ${ }^{45}$ Briefly, $500 \mathrm{mg}$ of lyophilized cells were extracted with $20 \mathrm{ml}$ of $80 \%$ (v/v) of aqueous methanol using ultrasound for $60 \mathrm{~min}$ at a temperature of $25{ }^{\circ} \mathrm{C}$ and an ultrasound frequency of $30 \mathrm{kHz}$. Ultrasonication was carried out using an ultrasonic bath USC1200TH (Prolabo; inner dimension: 300 $\mathrm{mm} \times 240 \mathrm{~mm} \times 200 \mathrm{~mm}$ ) with an electrical power of $400 \mathrm{~W}$ (i.e. acoustic power of $1 \mathrm{~W} \mathrm{~cm}^{-2}$ ), maximal heating power of $400 \mathrm{~W}$ and variable frequencies, equipped with a digital timer, a frequency and a temperature controller. Following centrifugation, the solid residue was discarded and the supernatant was subsequently evaporated to dryness at $40{ }^{\circ} \mathrm{C}$ and then resuspended in $1 \mathrm{ml}$ of $0.1 \mathrm{M}$ citrate-phosphate $\mathrm{pH} 4.8$ buffer containing 5 unit per $\mathrm{ml}$ of $\beta$-glucosidase from almonds (Sigma) for aglycones release during $4 \mathrm{~h}$ at $40{ }^{\circ} \mathrm{C}$. The extract was then centrifuged and the supernatant was filtered $(0.45 \mu \mathrm{m})$ before injection. Lignans and neolignans aglycones were quantified by RP-HPLC using a Varian liquid chromatographic system including Varian Prostar 230 pump, Metachem Degasit, Varian Prostar 410 autosampler and Varian Prostar 335 Photodiode Array Detector (PAD) and controlled by Galaxie version 1.9.3.2 software. The separation was performed at $35^{\circ} \mathrm{C}$ on a Purospher (Merck) RP-18 column $(250 \times 4.0 \mathrm{~mm}$ i.d.; $5 \mu \mathrm{m})$ and the separation conditions described by Renouard et al. ${ }^{46}$ The same extract was also analysis without enzymatic treatment appreciate the relative proportion of aglycones $v s$. glycosides.

\subsection{CE and RE-mediated biosynthesis of ZnO NPs}

For biosynthesis of ZnO NPs, zinc nitrate hexahydrate (SigmaAldrich) was used as a precursor of zinc ions $\left(\mathrm{Zn}^{2+}\right)$. Synthesis of $\mathrm{ZnO}$ NPs was carried out by following the protocol reported by Sangeetha et al. ${ }^{16}$ with little modifications. Briefly, $50 \mathrm{ml}$ of aqueous CE and RE of Flax were mixed separately with $50 \mathrm{ml}$ of $0.1 \mathrm{M}$ zinc nitrate solution (SNS) under constant stirring using magnetic stirrer. After complete dissolution of the mixtures, solutions were kept under vigorous stirring at $60^{\circ} \mathrm{C}$ for $3 \mathrm{~h}$. The dirty yellow precipitates formed in reaction mixtures were allowed to settle down at room temperature for $24 \mathrm{~h}$. Resulting supernatants were discarded and the remaining crude precipitates were centrifuged at $6000 \mathrm{rpm}$ for $15 \mathrm{~min}$. Again supernatants were discarded and the pellets formed were resuspended in distilled water followed by centrifugation at $6000 \mathrm{rpm}$ for $10 \mathrm{~min}$. This process of washing with distilled water was repeated thrice and the resulting pellets were oven dried at 
$80{ }^{\circ} \mathrm{C}$ for $6 \mathrm{~h}$. Dried pellets were separately crushed into fine powder and stored for further analysis.

\subsection{Characterization of $\mathrm{ZnO}$ NPs}

Optical properties of CE and RE-mediated ZnO NPs were characterized by using UV-visible spectroscopy. Biosynthesis of $\mathrm{ZnO}$ NPs was monitored as a function of time during the course of reaction with an interval of $30 \mathrm{~min}$. UV-vis spectra of the reaction mixtures were recorded on a HALO DB-20 spectrophotometer in the wavelength range of $230-800 \mathrm{~nm}$. Whereas, the stability of ZnO NPs was monitored by re-suspending $5 \mathrm{mg}$ of each type of biosynthesized-ZnO NPs (fine powder) separately in $5 \mathrm{ml}$ of distilled water. These aqueous suspensions were sonicated at room temperature ( $30 \mathrm{~min}$ ) for uniform dispersion of ZnO NPs. In order to evaluate the stability, UV-vis spectra of respective samples were recorded with an interval of one month for a time period of four months.

The crystalline nature of synthesized ZnO NPs were investigated by X-rays diffraction (XRD) analysis. Briefly, ZnO NPs were coated on XRD grid and the measurements were performed in the scanning mode by using X-ray diffractometer (ShimadzuModel, XRD-6000), operated at $40 \mathrm{kV}$ with a current of $30 \mathrm{~mA}$, and $\mathrm{Cu} / \mathrm{k} \alpha$ radiation in the range of $20-80^{\circ}$ in $2 \theta$ angles. The average particle size of the CE and RE-mediated ZnO NPs were calculated by using the Debye-Scherrer equation. ${ }^{47}$

$$
D=k \lambda / \beta \cos \theta
$$

where, $k=$ shape factor $(0.94) ; \lambda=$ X-ray wavelength $(\lambda=1.5418$ $\AA) ; \beta=$ full width at half maximum (FWHM) in radians; $\theta=$ Bragg's angle.

To find out the possible functional groups involved in the reduction and capping of $\mathrm{ZnO}$ NPs, reflectance spectra were recorded on Fourier transform infrared (FTIR) spectrophotometer (Bruker V70) working under a dehydrated airflow in reflectivity mode, attached with an attenuated total reflectance (ATR) accessory containing a gold crystal. Powder samples without any prior preparation were put simply on gold crystal and measurements were performed for wavenumber situated in the middle of the infrared range $\left(600-4500 \mathrm{~cm}^{-1}\right)$. Instrument resolution was about $4 \mathrm{~cm}^{-1}$ and measurements were average over 64 scans.

The morphology of ZnO NPs were observed by scanning electron microscope (SEM) by using the SIGMA model (MIRA3 TESCAN) operated at an accelerating voltage of $10 \mathrm{kV}$. The samples were prepared on a carbon coated copper grid by simply dropping a very small amount finely dispersed ZnO NPs on the grid. The film was then allowed to dry under a mercury lamp for $10 \mathrm{~min}$ and SEM images were collected at different magnifications. For elemental analysis, energy dispersive X-rays (EDX) analysis was performed by using EDX-detector attached with SEM.

\subsection{Antibacterial activities of ZnO NPs}

Antibacterial activities of $\mathrm{ZnO}$ NPs were evaluated against three multiple drug resistant bacterial strains i.e.; S. aureus (ATCC-
6538), E. coli (ATCC-15224), and K. pneumonia (ATCC-4619). These bacterial strains were obtained from the American Type Culture Collection (ATCC), University Boulevard Manassas, USA. The in vitro antibacterial activity was carried out with CE and RE-mediated ZnO NPs by well diffusion method. Briefly, each type of synthesized ZnO NPs were weighed $\left(10 \mu \mathrm{g} \mathrm{ml}{ }^{-1}\right)$ and dissolved in sterile distilled water, sonicated for $15 \mathrm{~min}$ and used immediately. The inoculums of bacterial strains were prepared by growing a single colony for overnight in nutrient broth. The nutrient agar plates were swabbed with bacterial strains broth, and $20 \mu \mathrm{l}$ of each synthesized-ZnO NPs $(10 \mu \mathrm{g}$ $\mathrm{ml}^{-1}$ ), 0.1 M ZNS (positive control), Amoxicillin as standard antibiotic $\left(10 \mu \mathrm{g} \mathrm{m} \mathrm{m}^{-1}\right)$, and aqueous $\mathrm{CE}$ and $\mathrm{RE}$ (negative controls) were added in wells. The plates were incubated at $37^{\circ} \mathrm{C}$ for $24 \mathrm{~h}$ in an incubator and the zone of inhibition ( $\mathrm{mm}$ ) was measured. Data were collected from three independent experiments for each strain and repeated twice.

\subsection{Antileishmanial activities of ZnO NPs}

In vitro antileishmanial activities of both type of synthesized $\mathrm{ZnO}$ NPs were evaluated against the promastigote forms of Leishmania major (MRHO/IR/76/ER) by using MTT [3-(4,5dimethylthiazol-2-yl)-2,5-diphenyl- $2 H$-tetrazolium bromide] assay (Sigma Chemical Co., St. Louis, Mo.). Leishmania major promastigotes were cultured in the RPMI 1640 medium supplemented with $10 \%$ fetal bovine serum (FBS), $292 \mu \mathrm{g} \mathrm{ml}{ }^{-1} \mathrm{~L}^{-}$ glutamine and $4.5 \mathrm{mg} \mathrm{ml}{ }^{-1}$ glucose (Sigma) at $25{ }^{\circ} \mathrm{C}$. The parasites were maintained in vitro by sub-passaging them every fifth day. Logarithmic phase Leishmania major promastigotes (1 $\times 10^{5}$ parasites per $\mathrm{ml}$ ) were seeded in 96-well flat-bottom plates. Then, $50 \mu \mathrm{l}$ of each concentration of ZnO NPs (25-250 $\mu \mathrm{g} \mathrm{m} \mathrm{m}^{-1}$ ) solutions prepared in PBS were added to triplicate wells and plates were incubated for 24 hours at $25^{\circ} \mathrm{C}$. Control wells contained $100 \mu$ l of RPMI 1640 media only. At the end of incubation, $10 \mu \mathrm{l}$ of MTT was added to each well and plates were further incubated for 3 hours at $25{ }^{\circ} \mathrm{C}$. Enzyme reaction was then stopped by the addition of $100 \mu \mathrm{l}$ of dimethyl sulfoxide (DMSO). The plates were incubated for an additional $30 \mathrm{~min}$ under agitation at room temperature. Relative optical density (OD) of the purple color due to formation of formazan was then measured at a wavelength of $540 \mathrm{~nm}$. The $50 \%$ inhibitory concentrations $\left(\mathrm{IC}_{50}\right)$ were determined by linear regression curve analysis.

\subsection{Statistical analysis}

All experiments were conducted in a synchronized manner and all experimental data was analyzed by Pareto analysis of variance (ANOVA). Duncan's multiple range test (DMRT, Windows version 7.5.1, SPSS Inc., Chicago) was used to determine the significance at $P<0.05 .{ }^{48}$

\section{Results and discussion}

\subsection{Phytochemical analysis}

Flax is known to be a rich source of biologically active secondary metabolites such as polyphenols, flavonoids, lignans and 
neolignans. ${ }^{\mathbf{2 4 , 2 5}}$ These bioactive compounds have been reported to exhibit strong antioxidant properties. ${ }^{26,27}$ Therefore, due to presence of these antioxidant-phytochemicals, Flax can serve as a potential source of reduction and stabilization during biosynthesis of ZnO NPs. Phytochemical analysis of in vitro cultures (CE and RE) of Flax showed significant variations in accumulation of TPC, TFC, lignans and neolignans (Table 1). In case of flavonoid production, CE accumulated higher levels of TFC (2.622 $\mathrm{mg} \mathrm{g}^{-1}$ ) than RE (1.162 $\mathrm{mg} \mathrm{g}^{-1}$ ) of Flax. However, RE was found to be more efficient in accumulation of TPC (9.913 $\left.\mathrm{mg} \mathrm{g}^{-1}\right)$, SDG (5.503 $\left.\mathrm{mg} \mathrm{g}^{-1}\right)$, LDG (11.902 $\left.\mathrm{mg} \mathrm{g}^{-1}\right)$, DCG $\left(21.603 \mathrm{mg} \mathrm{g}^{-1}\right)$, and GGCG (4.901 $\mathrm{mg} \mathrm{g}^{-1}$ ) than CE of Flax (Table 1). Similar results were reported by Gabr et al.,${ }^{\mathbf{4 9}}$ in which root culture showed higher production of phenolic and lignans than callus culture of Flax. Many other workers also reported that the root cultures of different plant species were more potent in production of antioxidant-phytochemicals than their respective callus cultures. ${ }^{39,50}$ These variations in the accumulation of phytochemicals in $\mathrm{CE}$ and RE of Flax might be due to difference in differentiated (root culture) and non-differentiated tissues (callus culture) or due to difference in culturing conditions (liquid/solid media). ${ }^{36,49}$ Differentiated tissues functionally transport oxygen and nutrients across the interior of the liquid media, and are closely related to secondary metabolism since certain level of differentiation is required for production and storage of certain types of secondary metabolites. ${ }^{39,40}$

\subsection{Biosynthesis and stability of $\mathrm{CE}$ and RE-mediated ZnO NPs monitored by UV-Vis spectroscopy}

The formation of $\mathrm{ZnO}$ NPs could be observed visually by monitoring the color change of reaction mixture from colorless to pale yellow during the course of reaction. Color of both reaction mixtures ( $\mathrm{CE}+\mathrm{ZNS}$ and $\mathrm{RE}+\mathrm{ZNS}$ ) changes from colorless to pale yellow within $1 \mathrm{~h}$, which is lesser as compared to many other previous reports. ${ }^{12,51}$ Biosynthesis of ZnO NPs was confirmed by recording UV-Vis spectra in the range of 230$800 \mathrm{~nm}$ wavelength. Due to surface plasmon resonance (SPR) properties, both types of synthesized ZnO NPs showed strong absorption peaks in the range of 345 to $352 \mathrm{~nm}$ (Fig. 2a).

Table 1 Phytochemical analysis of callus and root extract of Flax ${ }^{a}$

\begin{tabular}{llr}
\hline $\begin{array}{l}\text { Phytochemicals } \\
\left(\mathrm{mg} \mathrm{g}^{-1} \mathrm{DW}\right)\end{array}$ & $\begin{array}{l}\text { Callus extract } \\
(\text { mean } \pm \mathrm{SD})\end{array}$ & $\begin{array}{l}\text { Root extract } \\
(\text { mean } \pm \mathrm{SD})\end{array}$ \\
\hline & & \\
TPC & $5.502 \pm 0.061$ & $9.913 \pm 0.102$ \\
TFC & $2.622 \pm 0.011$ & $1.162 \pm 0.003$ \\
SDG & $2.201 \pm 0.010$ & $5.503 \pm 0.072$ \\
LDG & $7.502 \pm 0.082$ & $11.902 \pm 0.872$ \\
DGC & $4.505 \pm 0.022$ & $21.603 \pm 2.032$ \\
GGCG & $1.606 \pm 0.001$ & $4.9010 \pm 0.053$
\end{tabular}

${ }^{a}$ Values (mean $\pm \mathrm{SD}$ ) indicate the replicates of three experiments. Abbreviations: TPC, total phenolic content; TFC, total flavonoid content; SDG, secoisolariciresinol diglucoside; LDG, lariciresinol diglucoside; DGC, dehydrodiconiferyl alcohol glucoside; GGCG, guaiacylglycerol- $\beta$-coniferyl alcohol ether glucoside; SD, standard deviation.
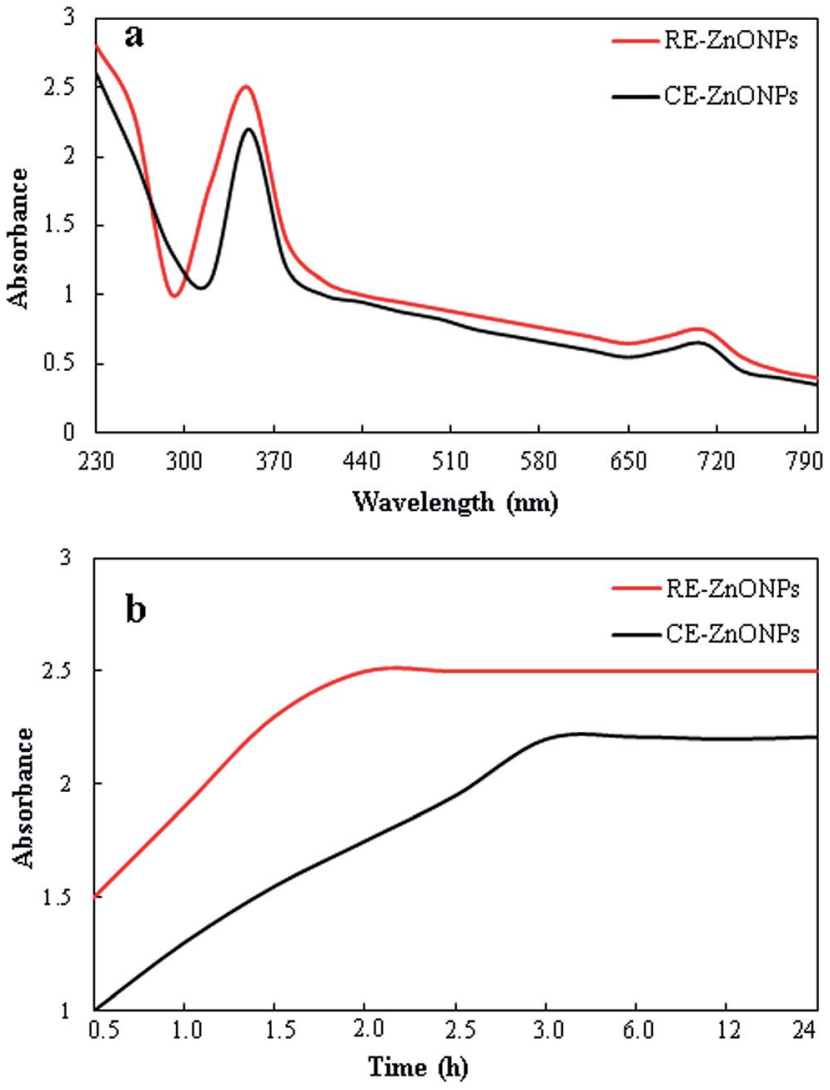

Fig. 2 UV-vis spectra of CE and RE-mediated ZnO NPs. (a) Absorption peaks of CE and RE-mediated ZnO NPs after $4 \mathrm{~h}$ (b) biosynthesis profiles of CE and RE-mediated ZnO NPs as a function time.

However, higher absorbance with comparatively narrow peak was observed in case of RE-mediated ZnO NPs. This might be due to smaller size and higher yield of RE-mediated ZnO NPs. ${ }^{38,52}$ In agreement with our results, similar UV absorption peaks of biosynthesized ZnO NPs have been reported previously. ${ }^{16,53}$ Generally, it is documented that the UV-Vis spectra could also be used to study the size and shape of nanoparticles in aqueous media. ${ }^{54}$ Absorbance of optical absorption peaks of nanoparticles generally decreases and shifted to longer wavelengths with increasing particle size. ${ }^{16}$ Moreover, the dielectric constant of the aqueous medium and the phytochemical adsorbed onto the surface of nanoparticles also take part in determination of spectral positions of plasmon absorption bands. ${ }^{55}$

To find out the reaction completion time of biosynthesis of ZnO NPs, we investigated the absorbance intensities and wavelength peaks of both reaction mixtures at different time intervals (30 min to $24 \mathrm{~h}$ ). In case of biosynthesis of CEmediated ZnO NPs, an expansion of reaction time was accompanied with an obvious increase in the absorbance intensity before $3 \mathrm{~h}$, but no significant enhancement in absorption was found after $3 \mathrm{~h}$. Whereas, in case of RE-mediated ZnO NPs, reaction was completed within $2 \mathrm{~h}$ and no significant change in absorbance intensity was observed until $24 \mathrm{~h}$ (Fig. 2b). Results showed that the biosynthesis of RE-mediated ZnO NPs was 
completed in shorter time than CE-mediated ZnO NPs. This might be due to higher amount of phytochemicals (TPC, TFC, lignans and neolignans) in $\mathrm{RE}$ as compared to $\mathrm{CE}$, which accelerate the reduction process of $\mathrm{Zn}^{2+}$ ions to $\mathrm{Zn}^{0}$. Nature and amount of phytochemicals present in plant extracts play crucial role in reduction and stabilization of nanoparticles.,56 Similar results were reported by many other workers during biosynthesis of silver nanoparticles. ${ }^{38,57}$

The stability of the both types of biosynthesized ZnO NPs was observed by re-suspending the dry powder nanoparticles in distilled water and keeping them at room temperature for four months. UV-Vis spectra of respective ZnO NPs did not showed any significant change in absorption peak or wavelength, which confirmed the stability of biosynthesized ZnO NPs. This showed that the phytochemicals present in CE and RE of Flax not only act as reducing agents but also stabilized the biosynthesized ZnO NPs by preventing them from agglomeration. Similar results were also reported in biosynthesis of metallic nanoparticles. ${ }^{12,38}$

\subsection{XRD analysis of CE and RE-mediated ZnO NPs}

The crystalline nature and phase purity of both types of biosynthesized ZnO NPs was confirmed by XRD analysis. XRD diffractogram of CE-mediated ZnO NPs (Fig. 3a) showed characteristic peaks at $31.75^{\circ}, 34.37^{\circ}, 36.19^{\circ}, 47.65^{\circ}, 56.51^{\circ}, 62.99^{\circ}$, and $67.93^{\circ}$, which can be attributed to $100,002,101,102,110$, 103 , and 200 reflection planes of hexagonal wurtzite structure of ZnO NPs (JCPDS 36-1451). ${ }^{58}$ Similarly, XRD diffractogram of REmediated ZnO NPs (Fig. 3b) showed diffraction peaks at $31.85^{\circ}$, $34.55^{\circ}, 36.33^{\circ}, 47.59^{\circ}, 56.67^{\circ}, 62.89^{\circ}$, and $68.03^{\circ}$, which are also in good agreement with 100, 002, 101, 102, 110, 103, and 200 reflection planes of hexagonal wurtzite structure of ZnO NPs. Previously, many studies also reported the hexagonal wurtzite structure of ZnO NPs. ${ }^{23,58}$ Strong intensity and narrow width of diffraction peaks of both types of synthesized ZnO NPs revealed that the resulting nanoparticles were highly crystalline in nature. Furthermore, diffraction peaks related to any impurity or secondary phase were not observed, indicating the superiority of proposed biosynthesis method over others for production of highly pure ZnO NPs.

Average crystallite size of both types of synthesized ZnO NPs was calculated by using the Debye-Scherrer equation. ${ }^{47}$ The average size was found to be $34.97 \mathrm{~nm}$ in case of RE-mediated ZnO NPs, while $61.44 \mathrm{~nm}$ in case of CE-mediated ZnO NPs. These results clearly showed that both types of biosynthesized ZnO NPs display the same crystalline structure (hexagonal) but vary in their sizes. RE-mediated ZnO NPs are smaller in size and therefore, thought to be more powerful in their antimicrobial action than CE-mediated ZnO NPs. It is generally recognized that the smaller size of nanoparticles make their penetration more easily into the microbial cells than larger size nanoparticles. ${ }^{59}$

\subsection{FTIR analysis of CE and RE-mediated ZnO NPs}

FTIR analysis was carried out to characterize and identify the possible interfacial phytochemicals involved in the bioreduction
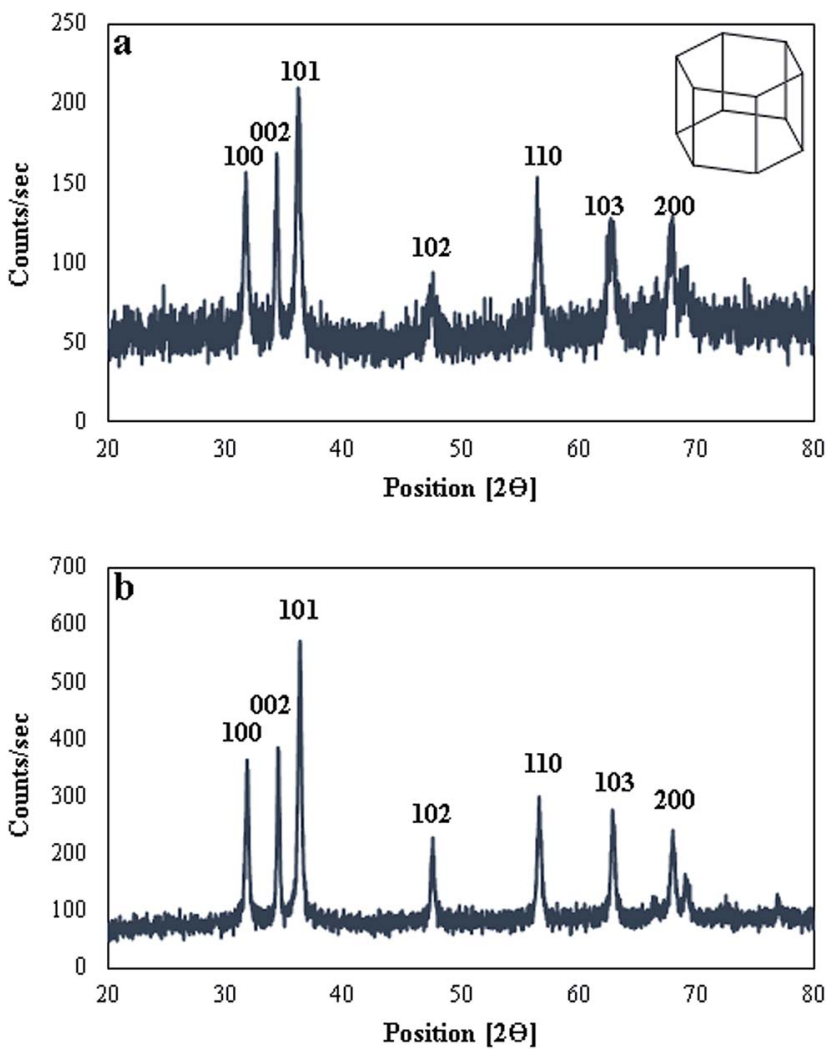

Fig. 3 XRD patterns of ZnO NPs. (a) CE-mediated ZnO NPs (b) REmediated ZnO NPs.

and capping of CE and RE-mediated ZnO NPs. FTIR spectra of $\mathrm{CE}$ and RE displayed a large number of peaks which reflect the complex nature of phytochemicals present in these extracts (Fig. 4). CE showed intense absorption peaks at about 811.99, 939.28, 1337.67, 1477.97, 1481.26, 1636.56, 1687.63, and 3186.25 $\mathrm{cm}^{-1}$ which correspond to the bond stretching of -OH (carboxylic acid), $-\mathrm{N}=\mathrm{O}$ (nitro group), $-\mathrm{C}-\mathrm{C}$ (aromatic ring), $-\mathrm{N}-\mathrm{H}$ (amine), $-\mathrm{C}=\mathrm{O}$ (carbonyl group) and $-\mathrm{O}-\mathrm{H}$ (phenol), respectively. Whereas, the CE-mediated ZnO NPs showed absorption peaks at about 896.85, 993.29, 1338.53, 1633.63, 1766.71, 2933.59 , and $3276.9 \mathrm{~cm}^{-1}$ which correspond to the involvement of carboxylic acid, nitro group, aromatic compounds, esters, carbonyl groups and phenols (Fig. 4a). ${ }^{\mathbf{1 2 , 1 6}}$ FTIR spectra of both $\mathrm{CE}$ and CE-mediated ZnO NPs showed almost similar absorption peaks, but the intensity of peaks in the region of $900-1600 \mathrm{~cm}^{-1}$ was greater in $\mathrm{CE}$ than $\mathrm{ZnO}$ NPs, suggesting the possible consumption of carboxylic, nitro and phenolic groups in the reduction and capping of CE-mediated ZnO NPs.

FTIR spectrum of RE showed strong absorption peaks at 811.99, 1029.93, 1186.16, 1282.60, 1415.68, 1581.55, 1943.23, and $3411.91 \mathrm{~cm}^{-1}$ which correspond to the vibrational bond stretching of $-\mathrm{C}-\mathrm{Cl}$ (alkyl halide), $-\mathrm{C}=\mathrm{C}-$ (alkenes), $-\mathrm{C}-\mathrm{N}-$ (aliphatic amine), $-\mathrm{N}=\mathrm{O}$ (nitro group) $-\mathrm{C}-\mathrm{H}$ (aromatic group), and $-\mathrm{O}-\mathrm{H}$ (phenol). ${ }^{56,58}$ Whereas, the RE-mediated ZnO NPs showed absorption peaks at about 896.85, 991.36, 1184.23, 1336.60, 1633.63, 2933.59, 3280.70, and $3589.36 \mathrm{~cm}^{-1}$ which also correspond to the similar functional groups as stated in RE 

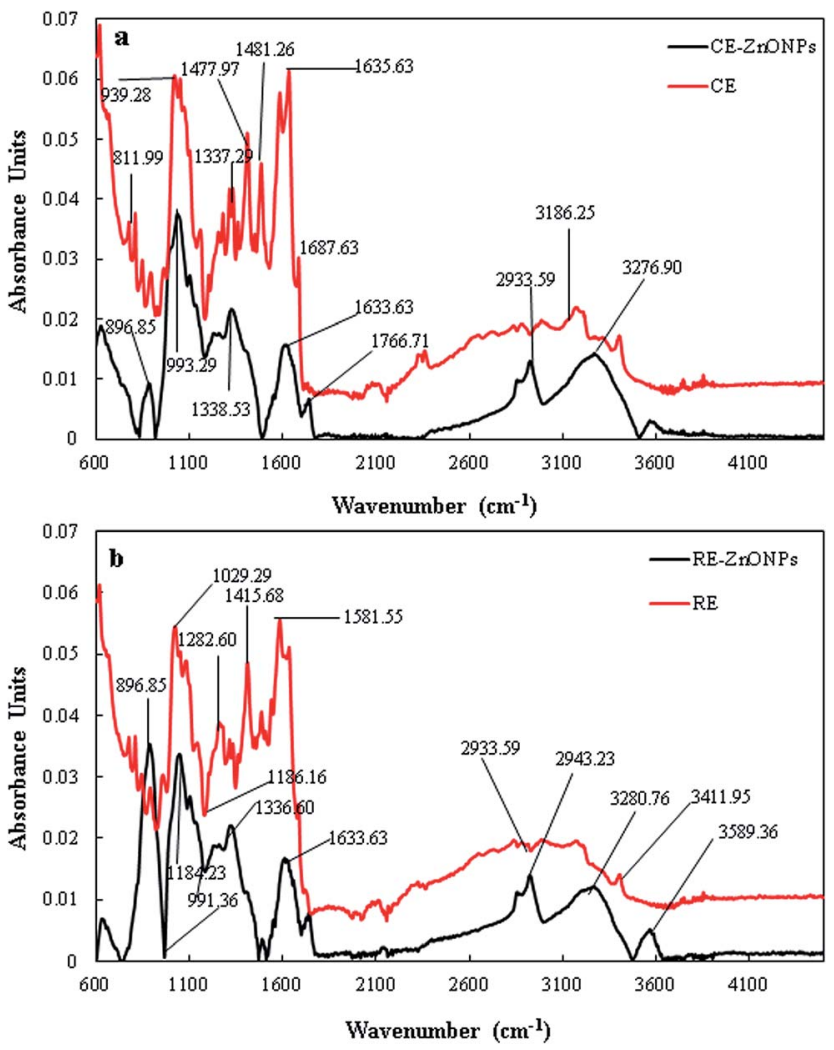

Fig. 4 FTIR spectra of extracts and ZnO NPs. (a) CE and CE-mediated ZnO NPs (b) RE and RE-mediated ZnO NPs.

(Fig. 4b). However, the sharpness and intensity of peaks was lower in spectrum of RE-mediated ZnO NPs in comparison to RE. Interestingly, the $1282.60(-\mathrm{OH})$ and $1415.68(-\mathrm{C}-\mathrm{H}) \mathrm{cm}^{-1}$ peaks present in RE spectrum were absent in RE-mediated $\mathrm{ZnO}$ NPs spectrum. So, we presume that the absence of these peaks may be attributed to the fact that the hydroxyl group (phenol) and aromatic rings are involved in the reduction of $\mathrm{Zn}^{2+}$ to $\mathrm{Zn}^{0}$. Our results are in good agreement with other reports available in the literature suggesting the possible involvement of above mentioned groups in bioreduction and capping of $\mathrm{ZnO}$ NPs. ${ }^{16,52,60}$ Moreover, the FTIR results also revealed that the both extracts (CE and RE) showed almost similar absorption peaks in the same region. However, RE showed some additional peaks in the region of 1000-1280 $\mathrm{cm}^{-1}$, suggesting the presence of some additional phytochemicals in RE than CE of Flax.

\subsection{SEM and EDX analysis of CE and RE-mediated ZnO NPs}

Morphology of both types of synthesized ZnO NPs was analyzed by SEM. CE-mediated ZnO NPs appeared nearly spherical in shape with weak agglomeration of particles (Fig. 5a). Whereas, the RE-mediated ZnO NPs appeared nearly hexagonal in shape with uniform distribution of particles (Fig. 5b). Similar to our results, different shapes of ZnO NPs have been reported previously, in which the spherical, rod, hexagonal and flower-like shapes were more common. ${ }^{2,60,61}$ Average particle size of $\mathrm{ZnO}$ NPs was calculated by Sigma Scan Pro software attached with SEM. CE-mediated ZnO NPs found to be in the range 29-37 nm

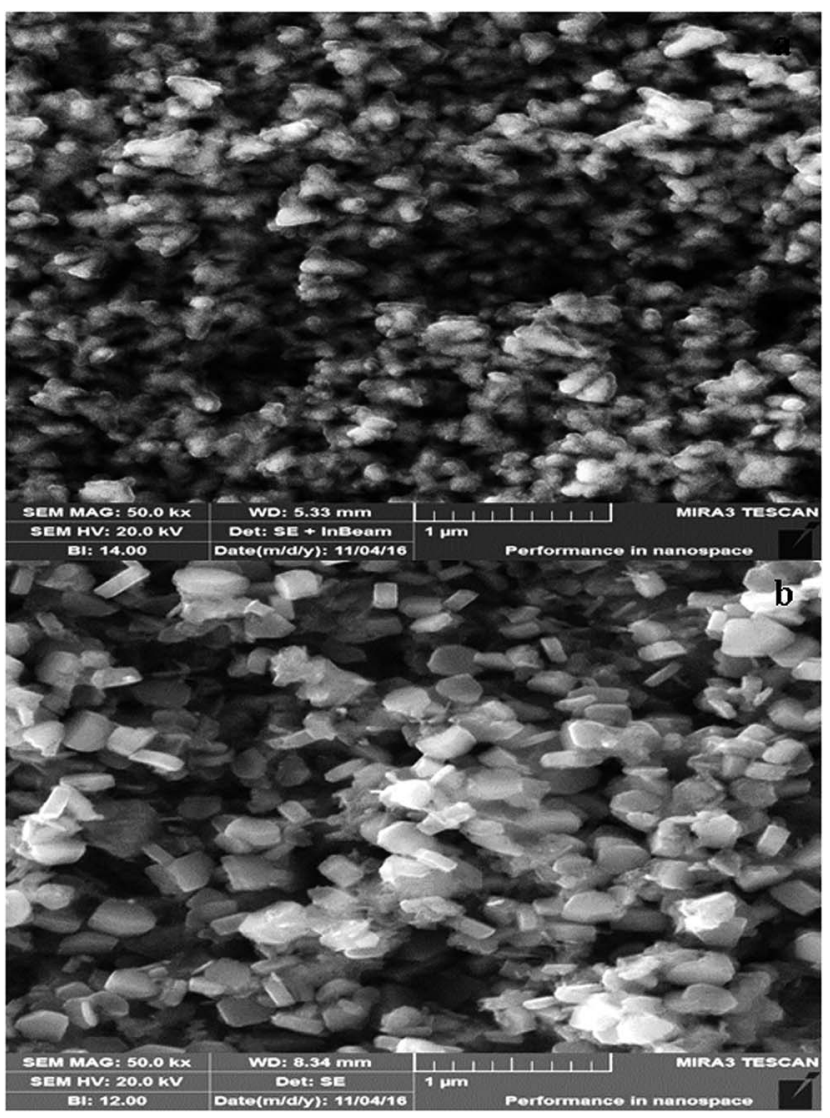

Fig. 5 SEM images of ZnO NPs. (a) CE-mediated ZnO NPs (b) REmediated ZnO NPs at $1 \mu \mathrm{m}$ magnification bar.

while RE-mediated ZnO NPs in 52-66 $\mathrm{nm}$. These results showed that the average particle size of both type of ZnO NPs determined by SEM was very close to the crystallite size calculated by XRD. Thus, the SEM results also endorsed the XRD results. Further, the elemental confirmation analysis of both types of synthesized ZnO NPs was carried out by EDX. EDX spectrum of CE-mediated ZnO NPs showed characteristic peaks of only zinc (79.80\%) and oxygen (20.20\%) elements (Fig. 6a). Similarly, EDX spectrum of RE-mediated ZnO NPs also showed the presence of only zinc (80.03\%) and oxygen (19.93\%) elements (Fig. 6b). These results are in agreement with previous reports. ${ }^{58,62}$ Absence of any extra peak in EDX spectra of both types of synthesized ZnO NPs, confirms the formation of pure ZnO NPs. ${ }^{63}$

\subsection{Probable mechanism involved in biosynthesis of $\mathrm{ZnO}$ NPs}

The possible mechanism involved in the biosynthesis of $\mathrm{ZnO}$ NPs by using plant extracts is not fully explored and yet under debate ${ }^{62}$ However, many studies have reported the involvement of plant metabolites containing polar groups in reduction and stabilization of metal oxide nanoparticles. ${ }^{64,65}$ In present study, FTIR analysis of CE and RE-mediated ZnO NPs revealed that the polyphenols, aromatic and carbonyl compounds are mainly responsible for reduction and surface capping of ZnO NPs. 

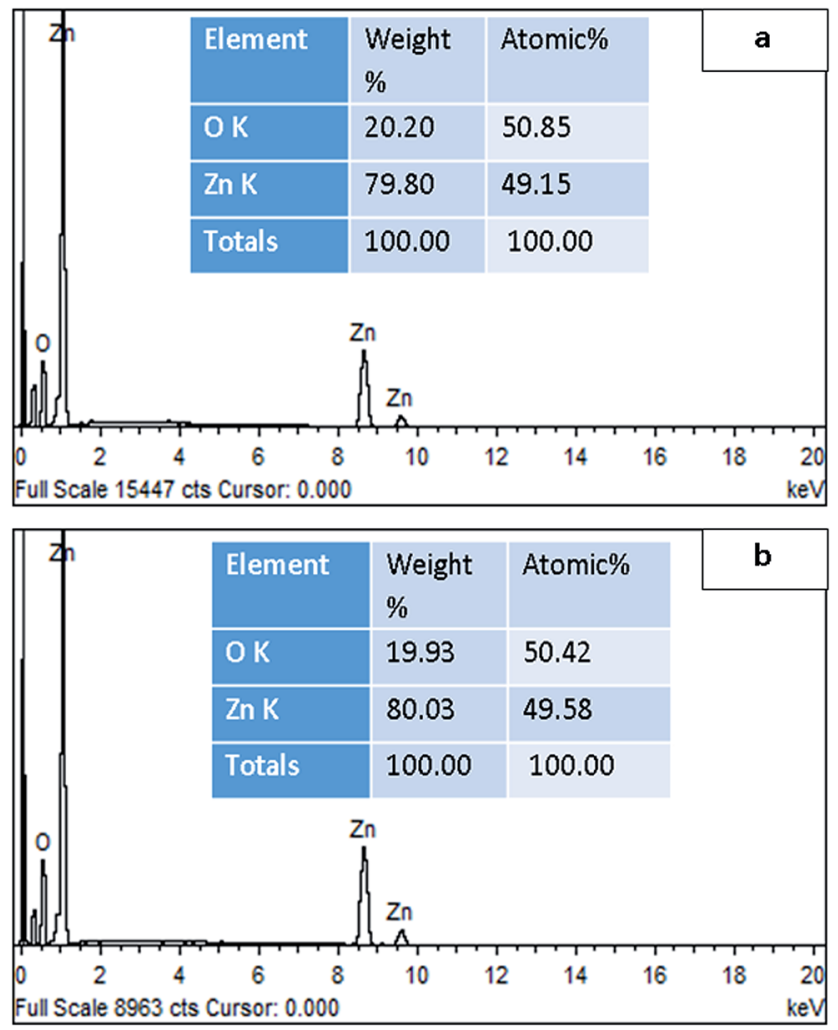

Fig. 6 EDX spectra of ZnO NPs. (a) CE-mediated ZnO NPs (b) REmediated ZnO NPs.

Phytochemical analysis revealed that the in vitro extracts (CE and RE) of Flax are also rich in phenolic, flavonoids, lignans (polyphenolics) and neolignans which are also in agreement with FTIR results. We, therefore, hypothesize the mechanism of biosynthesis of ZnO NPs by using the main lignan, SDG, which represent over $95 \%$ of total lignans present in Flax seeds. ${ }^{26}$ It seems that the polar groups $(\mathrm{OH})$ of SDG are involved in the reduction of $\mathrm{Zn}^{2+}$ to $\mathrm{Zn}^{0}$ ions. At first the lone pair electrons of the $\mathrm{OH}$ groups of SDG occupy empty orbitals of the $\mathrm{Zn}^{2+}$ ions and then result in complexation of $\mathrm{Zn}^{2+}$ by capping it with $\mathrm{OH}$ groups inside the nanoscopic templates of SDG. Lone pair electrons of $\mathrm{OH}$ groups of SDG result in reduction of $\mathrm{Zn}^{2+}$ ions and convert SDG molecule into its oxidized form. After this, heating of the reaction mixture resulted in biosynthesis of $\mathrm{ZnO}$ NPs along with the production of $\mathrm{NO}_{2}$ and $\mathrm{O}_{2}$ (Fig. 7a). Moreover, the other plant active compounds (PAC) present in the $\mathrm{CE}$ and RE capped and stabilized the synthesized ZnO NPs by making weak physical bonds with nanoparticles and prevent them from agglomeration (Fig. 7b). This proposed mechanism is in agreement with those reported earlier for biosynthesis of ZnO NPs by using polar groups of plant metabolites. ${ }^{64,66}$

\subsection{Antibacterial activities of CE and RE-mediated ZnO NPs}

Several studies have reported the non-toxicity and biocompatibility of ZnO NPs with human cells. ${ }^{67,68}$ This aspect of ZnO NPs make them most attractive and promising contenders against several microbes. In present study, antibacterial efficacy of both $\mathbf{a}$
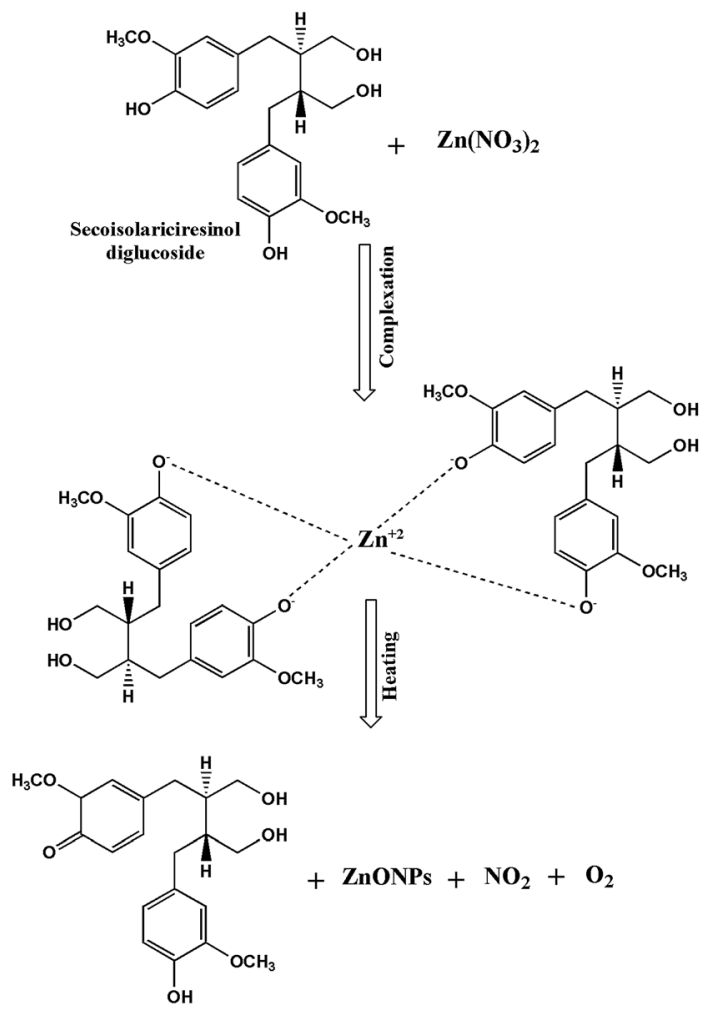

b

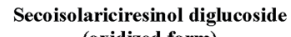
(oxidized form)

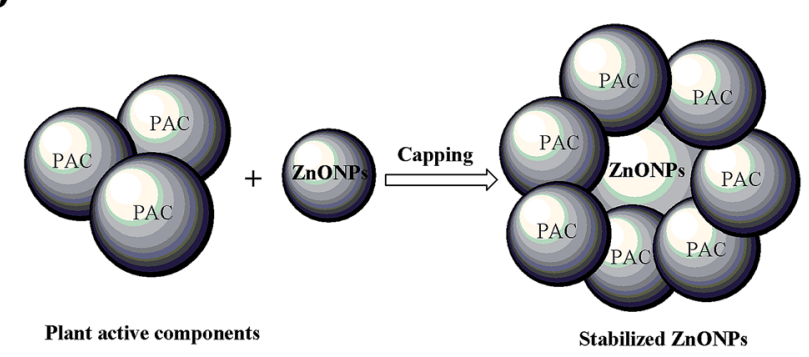

Fig. 7 Probable mechanism involved in biosynthesis and stability of $C E$ and RE-mediated ZnO NPs (a) complexation and reduction of zinc ions by using the main lignan (secoisolariciresinol diglucoside) present in in vitro extracts of Flax (b) stabilization of biosynthesized ZnO NPs by capping with plant active compounds (PAC).

types of synthesized ZnO NPs was evaluated against E. coli, $K$. pneumoniae, and $S$. aureus by using well diffusion method. Results showed that the both types of synthesized ZnO NPs exhibited prominent bactericidal activity against all three bacterial strains as compared to CE, RE and ZNS (Fig. 8). However, both types of synthesized ZnO NPs displayed strong bactericidal results against $S$. aureus as compared to E. coli and K. pneumoniae (Table 2). This might be due to difference in thickness and composition of cell walls and cell membranes of Gram-positive (S. aureus) and Gram-negative (E. coli and $K$. pneumoniae) bacteria. ${ }^{69,70}$ Similar to our results, more potent antibacterial effects of ZnO NPs against Gram-positive bacteria as compared to Gram-negative bacteria have been reported previously. ${ }^{59,70}$ Furthermore, it is clearly evident from results that the RE-mediated ZnO NPs showed higher level of 


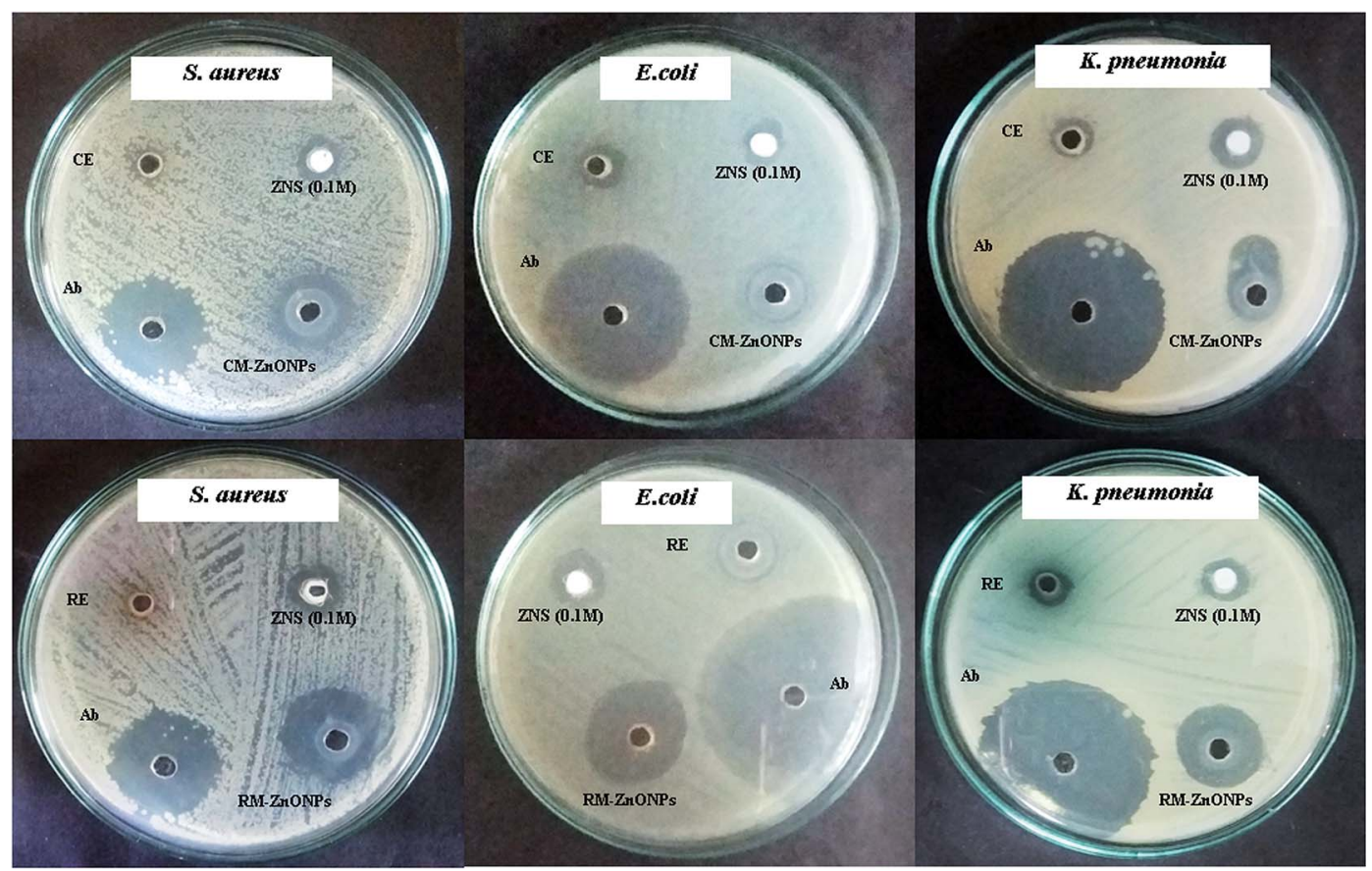

Fig. 8 Antibacterial assays of CE and RE-mediated ZnO NPs. Zone of inhibition against multiple drug resistant bacterial strains was measured in $\mathrm{mm}$.

Table 2 Antibacterial activity of CE and RE-mediated ZnONPs against multiple drug resistant bacterial strains ${ }^{a}$

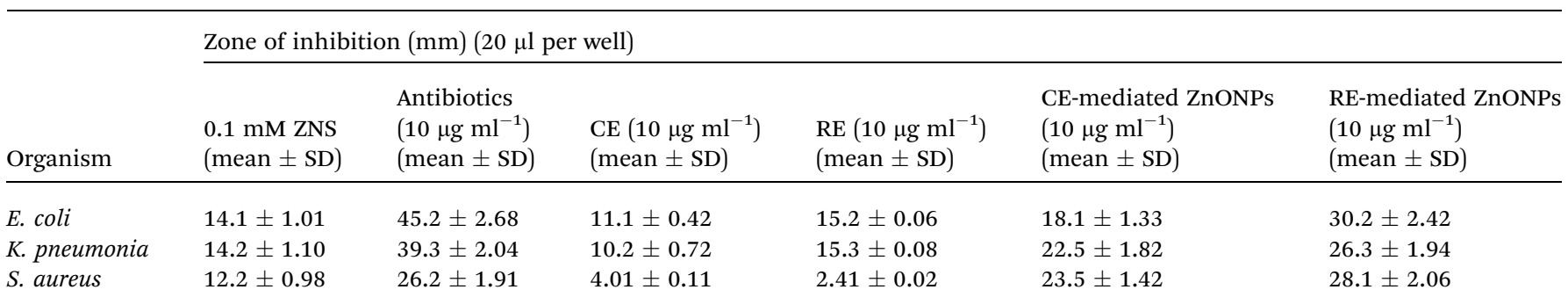

${ }^{a}$ Values (mean $\pm \mathrm{SD}$ ) indicate the replicates of three experiments. Abbreviations: ZnONPs, zinc oxide nanoparticles; RE, root extract; CE, callus extract; ZNS, zinc nitrate solution; SD, standard deviation.

bactericidal activity than CE-mediated ZnO NPs against all three types of bacterial strains (Fig. 8, Table 2). This might be attributed to the differences in their shapes, sizes and surface capping agents. The size and shape of the nanoparticles plays an important role in their biomedical applications. ${ }^{71}$ Previous studies have also shown that the smaller the size of ZnO NPs, the greater the efficacy in inhibiting the growth of bacteria by producing more ROS. ${ }^{71-73}$ Therefore, The smaller sized hexagonal RE-mediated ZnO NPs (34.97 nm) showed enhanced bactericidal activity against all the tested bacterial strains as compared to the larger sized spherical CE-mediated ZnO NPs $(61.44 \mathrm{~nm})$.

\subsection{Probable mechanism involved in antibacterial action of ZnO NPs}

Various probable mechanisms regarding antibacterial action of ZnO NPs have been proposed previously in literature. ${ }^{74,75}$ However, the precise mechanism involved in antibacterial action of ZnO NPs is not fully elaborated and still contentious. ${ }^{\mathbf{1 0 6 8}}$ Antibacterial action of ZnO NPs mainly depends on their size, shape, surface chemistry and distinct physicochemical properties. ${ }^{72,74,76}$ In present study, we proposed the probable mechanism involved in antibacterial action of biosynthesized ZnO NPs (Fig. 9). Due to their smaller size and electrostatic interaction with cell membrane of bacteria, ZnO NPs entered into the bacteria's cell. Once ZnO NPs have internalized bacterial cell, they start to interact with cellular organelles, causing intracellular depletion, and disruption of DNA replication by generating ROS (Fig. 9a-c). Excessive generation of metallic ions $\left(\mathrm{Zn}^{2+}\right)$ and ROS, mostly the hydroxyl radicals ( $\left.\mathrm{HO}^{\circ}\right)$, singlet oxygen $\left(\mathrm{O}_{2}{ }^{\circ}\right)$, and hydrogen peroxide $\left(\mathrm{H}_{2} \mathrm{O}_{2}\right)$ resulted in disruption and disorder of cell membrane. Consequently, the cell membrane damage leads to the cytoplasmic leakage and death of bacterial cells (Fig. 9d and e). Toxicity of ROS to bacteria is attributed to their high reactivity and oxidizing property. ${ }^{77}$ Similarly, several other studies have also reported 

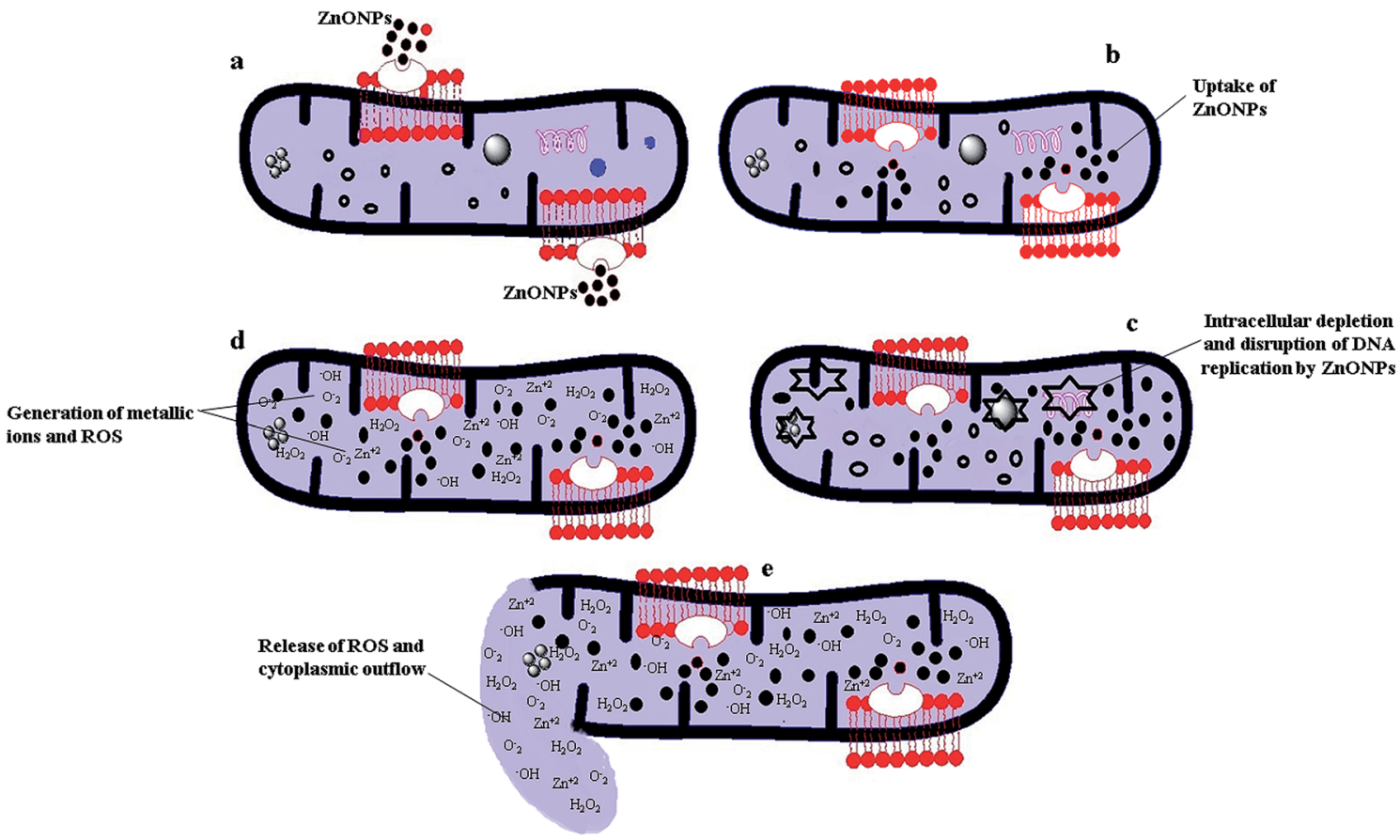

Fig. 9 Probable mechanism involved in antibacterial action of CE and RE-mediated ZnO NPs. (a) Interactions of ZnO NPs with cell wall and cell membrane of bacteria (b) entrance of ZnO NPs into the bacteria's cell (c) taking hold of all intracellular activities of bacteria's cell by ZnO NPs (d) generation of free metallic ions $\left(\mathrm{Zn}^{2+}\right)$ and ROS (e) damage of cell membrane and ROS outflow along with cytoplasmic leakage.

the generation of ROS as the main mechanism responsible for antibacterial activity of ZnO NPs. ${ }^{10,68,76}$

\subsection{Antileishmanial activities of $\mathrm{CE}$ and RE-mediated ZnO NPs}

Due to the emergence of infectious diseases and antibiotic resistance in pathogenic microbes, the pharmaceutical industries and scientists are looking for new antimicrobial agents. In present scenario, ZnO NPs emerged as the most promising contenders not only in fighting against various microbes but also in tackling infectious diseases due to their unique broadspectrum bioactivities. ${ }^{\mathbf{1 0 1 1}}$ In present study, we evaluated the antileishmanial activity of biosynthesized CE and RE-mediated ZnO NPs against promastigote forms of Leishmania major. The leishmanicidal potency of different concentrations (25-250 $\mu \mathrm{g}$ $\mathrm{ml}^{-1}$ ) of both types of ZnO NPs was tested for $24 \mathrm{~h}$ and the data was expressed as percentage inhibition of parasites. Results showed that the metabolic activities of Leishmania major promastigotes exposed to ZnO NPs changed with the passage of time as compared to control group. Formation of purple colored formazan crystals during MIT assay is a sign of metabolic activity, indicating that parasites are alive and maintaining their metabolism. ${ }^{7}$ In control group, dark purple formazan crystals were visually observed. However, in case of ZnO NPs exposedpromastigotes, formazan crystals appeared in very small amount (light purple color), indicating that the ZnO NPs inhibited the metabolic activities of the majority of the parasites.

Quantitatively, a dose-dependent effect of various concentrations of both types of ZnO NPs was observed. Higher concentration $\left(250 \mu \mathrm{g} \mathrm{ml}^{-1}\right)$ of both types of ZnO NPs showed highest percentage inhibition of parasites as compared to lower concentrations. However, $250 \mu \mathrm{g} \mathrm{ml}^{-1}$ of RE-mediated ZnO NPs showed 1.68 -fold increase in inhibition (37\%) of parasites as compared to CE-mediated ZnO NPs (22\%) (Fig. 10). A dosedependent increase in antileishmanial activity have also been reported previously in many studies. ${ }^{7,8}$ The $\mathrm{IC}_{50}$ value of REmediated ZnO NPs (266.89) was also 1.47-times less than that of CE-mediated ZnO NPs (393.62). Both the percentage inhibition and $\mathrm{IC}_{50}$ values revealed the strong leishmanicidal activity

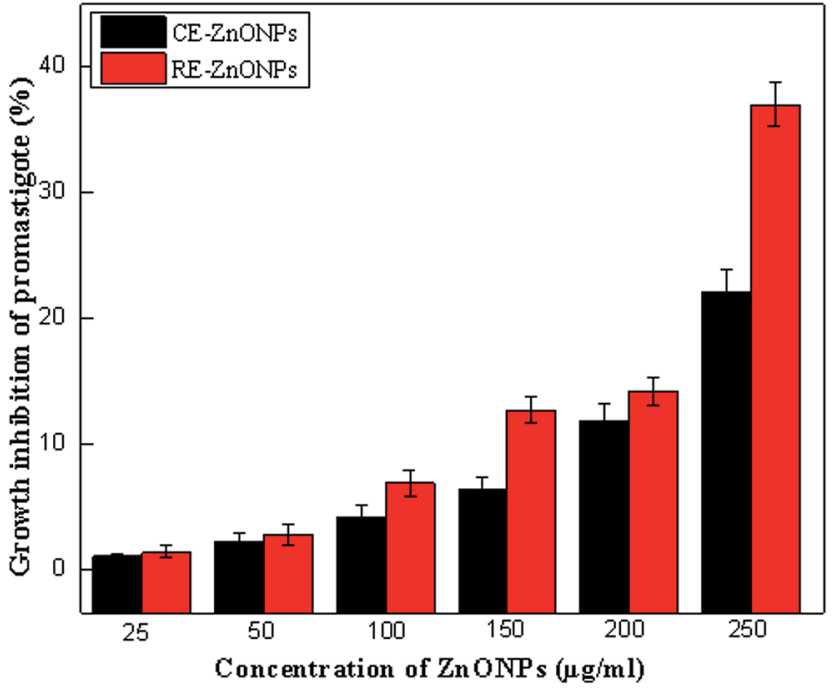

Fig. 10 Antileshmanial activity of different concentration of CE and $\mathrm{RE}$-mediated ZnO NPs calculated as percentage inhibition of parasites. 
of RE-mediated ZnO NPs as compared to CE-mediated ZnO NPs. This might be due to the differences in their shapes, sizes and stabilizing agents, as described earlier in antibacterial activity. In agreement with our results, many studies have shown that the smaller the size of nanoparticles, the greater the efficacy in inhibiting the Leishmania parasites by producing more ROS. $^{78,79}$ Different types of metal and metal oxide nanoparticles are reported to generate a high level of ROS, which promote the process of apoptosis. ${ }^{\mathbf{8} 80,81}$ It is well known fact that the Leishmania parasite are highly sensitive to ROS and any drug/agent that could generate ROS would be a promising antileishmanial contender. ${ }^{82} \mathrm{ZnO}$ NPs act as large reservoir of ROS $\left(\mathrm{OH}^{-}, \mathrm{H}_{2} \mathrm{O}_{2}, \mathrm{O}^{2-}\right.$, etc $)$ and free $\mathrm{Zn}^{2+}$ ions, which could lead to intracellular damaging of Leishmania parasites.

\section{Conclusions}

Exploitation of in vitro cultures of Flax could serve as a novel and rich source of phytochemical reducing agents for enhanced biosynthesis of ZnO NPs. The UV-Vis spectroscopy, XRD, SEM, EDX, and FTIR analysis revealed that RE-mediated ZnO NPS proved to be more efficient than CE-mediated ZnO NPs not only in term of their physicals properties such as shape, size, crystallinity and distribution but also in antibacterial and antileishmanial activities. The difference in the physical properties and bio-potential assays of both type of synthesized ZnO NPs is attributed to the differential effects of in vitro cultures of Flax on accumulation of bioactive phytochemicals responsible for capping and stabilization of nanoparticles. These biologically synthesized ZnO NPs are free from toxic chemicals that are usually entangled on the surfaces of chemically synthesized nanoparticles and therefore safe to use in various biomedical and pharmaceutical industries.

\section{Ethical compliance}

This study was approved by the research ethical committee of Department of Biotechnology, Quaid-i-Azam University Islamabad, Pakistan.

\section{Conflict of interest}

The authors declare no conflict of interest.

\section{Abbreviations}

$\begin{array}{ll}\text { ZnO NPs } & \text { Zinc oxide nanoparticles } \\ \text { CE } & \text { Callus extract } \\ \text { RE } & \text { Root extract } \\ \text { ZNS } & \text { Zinc nitrate solution } \\ \text { MS } & \text { Murashige and Skoog medium } \\ \text { TPC } & \text { Total phenolic content } \\ \text { TFC } & \text { Total flavonoid content } \\ \text { SDG } & \text { Secoisolariciresinol diglucoside } \\ \text { LDG } & \text { Lariciresinol diglucoside } \\ \text { DCG } & \text { Dehydrodiconiferyl alcohol glucoside }\end{array}$

GGCG Guaiacylglycerol- $\beta$-coniferyl alcohol ether glucoside DW Dry weight

PGRs Plant growth regulators

UV-vis Ultra violet-visible

FTIR Fourier-transform infrared

XRD X-ray diffraction

SEM Scanning electron microscopy

EDX Energy dispersive X-rays

ATCC American Type Culture Collection

\section{References}

1 S. Ahmed and S. Ikram, J. Photochem. Photobiol., B, 2016, 161, 141-153.

2 M. Ramesh, M. Anbuvannan and G. Viruthagiri, Spectrochim. Acta, Part A, 2015, 136, 864-870.

3 Z. Deng, M. Chen, G. Gu and L. Wu, J. Phys. Chem. B, 2008, 112, 16-22.

4 J. Guo and C. Peng, Ceram. Int., 2015, 41, 2180-2186.

5 H. Mirzaei and M. Darroudi, Ceram. Int., 2017, 43, 907-914. 6 S. J. Yang and C. R. Park, Nanotechnology, 2007, 19, 035609.

7 A. M. Allahverdiyev, E. S. Abamor, M. Bagirova, S. Y. Baydar, S. C. Ates, F. Kaya, C. Kaya and M. Rafailovich, Exp. Parasitol., 2013, 135, 55-63.

8 A. M. Allahverdiyev, E. S. Abamor, M. Bagirova, C. B. Ustundag, C. Kaya, F. Kaya and M. Rafailovich, Int. J. Nanomed., 2011, 6, 2705-2714.

9 R. Reithinger and J.-C. Dujardin, J. Clin. Microbiol., 2007, 45, 21-25.

10 R. Jalal, E. K. Goharshadi, M. Abareshi, M. Moosavi, A. Yousefi and P. Nancarrow, Mater. Chem. Phys., 2010, 121, 198-201.

11 M. Rai, A. Yadav and A. Gade, Biotechnol. Adv., 2009, 27, 76-83.

12 K. Elumalai, S. Velmurugan, S. Ravi, V. Kathiravan and S. Ashokkumar, Spectrochim. Acta, Part A, 2015, 143, 158-164.

13 G. Nohynek, E. Dufour and M. Roberts, Skin Pharmacol. Physiol., 2008, 21, 136-149.

14 G. J. Nohynek, J. Lademann, C. Ribaud and M. S. Roberts, Crit. Rev. Toxicol., 2007, 37, 251-277.

15 A. Dakhlaoui, M. Jendoubi, L. S. Smiri, A. Kanaev and N. Jouini, J. Cryst. Growth, 2009, 311, 3989-3996.

16 G. Sangeetha, S. Rajeshwari and R. Venckatesh, Mater. Res. Bull., 2011, 46, 2560-2566.

17 S. Ameen, M. S. Akhtar and H. S. Shin, Mater. Lett., 2015, 155, 82-86.

18 F. Thema, E. Manikandan, M. Dhlamini and M. Maaza, Mater. Lett., 2015, 161, 124-127.

19 A. K. Zak, R. Razali, W. Majid and M. Darroudi, Int. J. Nanomed., 2011, 6, 1399-1403.

20 S. Shamaila, A. K. L. Sajjad, S. A. Farooqi, N. Jabeen, S. Majeed and I. Farooq, Applied Materials Today, 2016, 5, 150-199.

21 S. P. Chandran, M. Chaudhary, R. Pasricha, A. Ahmad and M. Sastry, Biotechnol. Prog., 2006, 22, 577-583.

22 L. Christensen, S. Vivekanandhan, M. Misra and A. K. Mohanty, Adv. Mater. Lett., 2011, 2, 429-434. 
23 D. Gnanasangeetha and D. SaralaThambavani, Res. J. Mater. Sci., 2013, 2320, 6055.

24 T. J. Schmidt, M. Klaes and J. Sendker, Phytochemistry, 2012, 82, 89-99.

25 H. Wang, J. Wang, C. Qiu, Y. Ye, X. Guo, G. Chen, T. Li, Y. Wang, X. Fu and R. H. Liu, Food Chem., 2017, 214, 227-233.

26 J. Attoumbré, S. Charlet, S. Baltora-Rosset, C. Hano, S. Raynaud-Le Grandic, F. Gillet, L. Bensaddek, F. Mesnard and M.-A. Fliniaux, Plant Cell Rep., 2006, 25, 859-864.

27 C. Hano, M. Addi, L. Bensaddek, D. Crônier, S. BaltoraRosset, J. Doussot, S. Maury, F. Mesnard, B. Chabbert and S. Hawkins, Planta, 2006, 223, 975-989.

28 M. Szewczyk, S. Abarzua, A. Schlichting, B. Nebe, B. Piechulla, V. Briese and D.-U. Richter, J. Med. Plants Res., 2014, 8, 237-245.

29 V. Beejmohun, O. Fliniaux, C. Hano, S. Pilard, E. Grand, D. Lesur, D. Cailleu, F. Lamblin, E. Lainé and J. Kovensky, Phytochemistry, 2007, 68, 2744-2752.

30 R. Dobrucka and J. Długaszewska, Saudi J. Biol. Sci., 2016, 23, 517-523.

31 P. Rajiv, S. Rajeshwari and R. Venckatesh, Spectrochim. Acta, Part A, 2013, 112, 384-387.

32 H. A. Salam, R. Sivaraj and R. Venckatesh, Mater. Lett., 2014, 131, 16-18.

33 N. A. Samat and R. M. Nor, Ceram. Int., 2013, 39, S545-S548. 34 R. P. Singh, V. K. Shukla, R. S. Yadav, P. K. Sharma, P. K. Singh and A. C. Pandey, Adv. Mater. Lett., 2011, 2, 313-317.

35 S. Vijayakumar, G. Vinoj, B. Malaikozhundan, S. Shanthi and B. Vaseeharan, Spectrochim. Acta, Part A, 2015, 137, 886-891. 36 M. A. Khan, B. H. Abbasi, N. A. Shah, B. Yücesan and H. Ali, Plant Cell, Tissue Organ Cult., 2015, 123, 501-510.

37 R. V. Reis, A. P. P. L. Borges, T. P. C. Chierrito, E. R. de Souto, L. M. de Souza, M. Iacomini, A. J. B. de Oliveira and R. A. C. Gonçalves, Plant Cell, Tissue Organ Cult., 2011, 106, 329-335.

38 S. Anjum and B. H. Abbasi, Int. J. Nanomed., 2016, 11, 715.

39 X.-H. Cui, D. Chakrabarty, E.-J. Lee and K.-Y. Paek, Bioresour. Technol., 2010, 101, 4708-4716.

40 N. Praveen and H. Murthy, Acta Physiol. Plant., 2010, 32, 1017-1022.

41 T. Murashige and F. Skoog, Physiol. Plant., 1962, 15, 473-497. 42 S. Anjum and B. H. Abbasi, Int. J. Nanomed., 2016, 11, 1663. 43 Y. Velioglu, G. Mazza, L. Gao and B. Oomah, J. Agric. Food Chem., 1998, 46, 4113-4117.

44 C.-C. Chang, M.-H. Yang, H.-M. Wen and J.-C. Chern, J. Food Drug Anal., 2002, 10, 178-182.

45 C. Corbin, T. Fidel, E. A. Leclerc, E. Barakzoy, N. Sagot, A. Falguiéres, S. Renouard, J.-P. Blondeau, C. Ferroud and J. Doussot, Ultrason. Sonochem., 2015, 26, 176-185.

46 S. Renouard, C. Hano, C. Corbin, O. Fliniaux, T. Lopez, J. Montguillon, E. Barakzoy, F. Mesnard, F. Lamblin and E. Lainé, Food Chem., 2010, 122, 679-687.

47 S. Arokiyaraj, M. V. Arasu, S. Vincent, N. U. Prakash, S. H. Choi, Y.-K. Oh, K. C. Choi and K. H. Kim, Int. J. Nanomed., 2014, 9, 379.

48 D. B. Duncan, Biometrics, 1955, 11, 1-42.
49 A. M. Gabr, H. B. Mabrok, K. Z. Ghanem, M. Blaut and I. Smetanska, Plant Cell, Tissue Organ Cult., 2016, 126, 255-267.

50 M. Kikowska, B. Thiem, E. Sliwinska, M. Rewers, M. Kowalczyk, A. Stochmal and W. Oleszek, J. Plant Growth Regul., 2014, 33, 809-819.

51 N. Bala, S. Saha, M. Chakraborty, M. Maiti, S. Das, R. Basu and P. Nandy, RSC Adv., 2015, 5, 4993-5003.

52 A. K. Jha and K. Prasad, Adv. Mater. Lett., 2014, 5, 501-505.

53 F. Fan, Y. Feng, P. Tang and D. Li, Mater. Lett., 2015, 158, 290-294.

54 W. Raut Rajesh, R. Lakkakula Jaya, S. Kolekar Niranjan, D. Mendhulkar Vijay and B. Kashid Sahebrao, Curr. Nanosci., 2009, 5, 117-122.

55 S. Smitha, K. Nissamudeen, D. Philip and K. Gopchandran, Spectrochim. Acta, Part A, 2008, 71, 186-190.

56 P. Jamdagni, P. Khatri and J. Rana, J. King Saud Univ., Sci., 2016, DOI: 10.1016/j.jksus.2016.10.002.

57 S. Sheshadri, S. Sriram, P. Balamurugan, R. Anupriya, S. A. Princy, P. Brindha and S. Bindu, RSC Adv., 2015, 5, $47548-47554$.

58 L. Fu and Z. Fu, Ceram. Int., 2015, 41, 2492-2496.

59 A. Sirelkhatim, S. Mahmud, A. Seeni, N. H. M. Kaus, L. C. Ann, S. K. M. Bakhori, H. Hasan and D. Mohamad, Nano-Micro Lett., 2015, 7, 219-242.

60 B. Banumathi, B. Malaikozhundan and B. Vaseeharan, Vet. Parasitol., 2016, 216, 93-100.

61 M. F. Khan, M. Hameedullah, A. H. Ansari, E. Ahmad, M. Lohani, R. H. Khan, M. M. Alam, W. Khan, F. M. Husain and I. Ahmad, Int. J. Nanomed., 2014, 9, 853.

62 N. J. Sushma, B. Mahitha, K. Mallikarjuna and B. D. P. Raju, Appl. Phys. A: Mater. Sci. Process., 2016, 122, 1-10.

63 K. Vimala, S. Sundarraj, M. Paulpandi, S. Vengatesan and S. Kannan, Process Biochem., 2014, 49, 160-172.

64 F. Buazar, M. Bavi, F. Kroushawi, M. Halvani, A. KhalediNasab and S. Hossieni, J. Exp. Nanosci., 2016, 11, 175-184.

65 S. Ghayempour and M. Montazer, Ultrason. Sonochem., 2017, 34, 458-465.

66 S. Jafarirad, M. Mehrabi, B. Divband and M. Kosari-Nasab, Mater. Sci. Eng., Proc. Conf., 2016, 59, 296-302.

67 G. Colon, B. C. Ward and T. J. Webster, J. Biomed. Mater. Res., Part A, 2006, 78, 595-604.

68 N. Padmavathy and R. Vijayaraghavan, Sci. Technol. Adv. Mater., 2008, 9, 035004.

69 Y. Bibi, S. Nisa, F. M. Chaudhary and M. Zia, BMC Complementary Altern. Med., 2011, 11, 52.

70 A. Azam, A. Ahmed, M. Oves, M. Khan, S. Habib and A. Memic, Int. J. Nanomed., 2012, 7, 6003-6009.

71 K. R. Raghupathi, R. T. Koodali and A. C. Manna, Langmuir, 2011, 27, 4020-4028.

72 N. Jones, B. Ray, K. T. Ranjit and A. C. Manna, FEMS Microbiol. Lett., 2008, 279, 71-76.

73 N. Salah, S. S. Habib, Z. H. Khan, A. Memic, A. Azam, E. Alarfaj, N. Zahed and S. Al-Hamedi, Int. J. Nanomed., 2011, 6, 863.

74 R. Brayner, R. Ferrari-Iliou, N. Brivois, S. Djediat, M. F. Benedetti and F. Fiévet, Nano Lett., 2006, 6, 866-870. 
75 J. Díaz-Visurraga, C. Gutiérrez, C. Von Plessing and A. García, Science And Technology Against Microbial Pathogens: Research, Development and Evaluation, Formatex: Badajoz, 2011, 210-218.

76 O. Yamamoto, Int. J. Inorg. Mater., 2001, 3, 643-646.

77 H. Zhang, X. Lv, Y. Li, Y. Wang and J. Li, ACS Nano, 2009, 4, 380-386.

78 A. Ahmad, Y. Wei, F. Syed, S. Khan, G. M. Khan, K. Tahir, A. U. Khan, M. Raza, F. U. Khan and Q. Yuan, J. Photochem. Photobiol., B, 2016, 161, 17-24.
79 V. Kumar, R. K. Gundampati, D. K. Singh, M. V. Jagannadham, S. Sundar and S. H. Hasan, J. Ind. Eng. Chem., 2016, 37, 224-236.

80 Y. Li, W. Zhang, J. Niu and Y. Chen, ACS Nano, 2012, 6, 51645173.

81 P. Saini, S. K. Saha, P. Roy, P. Chowdhury and S. P. S. Babu, Exp. Parasitol., 2016, 160, 39-48.

82 H. W. Murray, J. Exp. Med., 1981, 153, 1302-1315. 